\title{
HOMOCYSTINURIA AND MARFAN'S SYNDROME
}

\section{A Comparison}

\author{
D. P. Brenton and C. J. Dow, London, England \\ Departments of Human Metabolism and Radiology, University College Hospital, London \\ and \\ J. I. P. James, R. L. Hay and Ruth Wynne-Davies, Edinburgh, Scotland \\ Department of Orthopaedic Surgery, University of Edinburgh
}

At intervals over the last two years the authors have worked together on problems relating to these two diseases, homocystinuria being extensively studied in the Department of Human Metabolism, University College Hospital, London, and Marfan's syndrome being surveyed in the Heritable Diseases Clinic at the Princess Margaret Rose Orthopaedic Hospital, Edinburgh. Because of their skeletal abnormalities, patients with either disease may present to the orthopaedic surgeon, and the purpose of this paper is to describe the skeletal and radiological features of twenty-three patients-twenty-two London cases (D. P. B.) and one from Edinburgh - with homocystinuria and compare them with those found in a series of sixteen patients with Marfan's syndrome.

In 1896 Marfan described the syndrome now known by his name, later called arachnodactyly by Achard and Grenet (1902). The latter term is not a good one in that arachnodactyly may not be present and is not exclusive to this condition. Since that time many cases have been described and it is now recognised as not being excessively rare. It is clear also that it is of autosomal dominant inheritance (Weve 1931, McKusick 1966). Its three commonest features are overgrowth of long bones, ocular lens dislocation and aortic aneurysm.

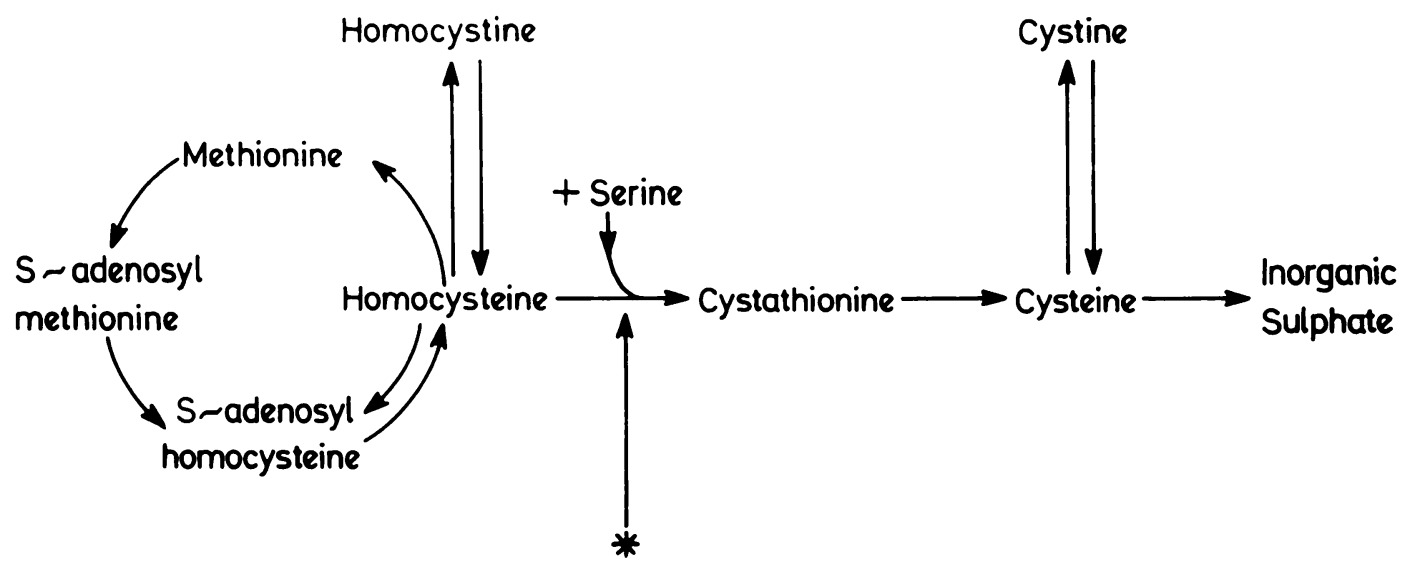

Fig. 1

The metabolic block in homocystinuria. A simplified metabolic scheme of the conversion of methionine to cysteine. Cystathionine synthase, the deficient or defective enzyme in homocystinuria, catalyses the formation of cystathionine from homocysteine and serine.

Homocystinuria is inherited as an autosomal recessive disorder and is an inborn error of sulphur amino acid metabolism characterised clinically by lens dislocation, mental retardation, skeletal abnormalities and a thrombotic tendency. The disease was first described by Field, Carson, Cusworth, Dent and Neill (1962) and independently by Gerritsen and Waisman (1964). The former authors noted pes cavus, genu valgum, scoliosis and sternal deformities. The

VOL. 54 B, NO. 2, MAY 1972 
combination of lens dislocation and these skeletal abnormalities gave to some patients with homocystinuria a strong resemblance to those with Marfan's syndrome. Carson, Dent, Field and Gaull (1965), reporting the clinical features in ten patients with homocystinuria from Northern Ireland, pointed out that two of their patients had previously been reported in the literature as cases of Marfan's syndrome. The logical step of screening all patients with Marfan's syndrome for homocystine in the urine was carried out by McKusick in Baltimore at the suggestion of Professor C. E. Dent. This led to the discovery of the largest series of patients with homocystinuria yet reported in the literature, thirty-eight (Schimke, McKusick, Huang and Pollack 1965).

\section{SELECTION AND DIAGNOSIS OF PATIENTS}

Homocystinuria is an inborn error of methionine metabolism (Fig. 1) resulting from a deficiency of the enzyme cystathionine synthetase. As a result of this metabolic block,

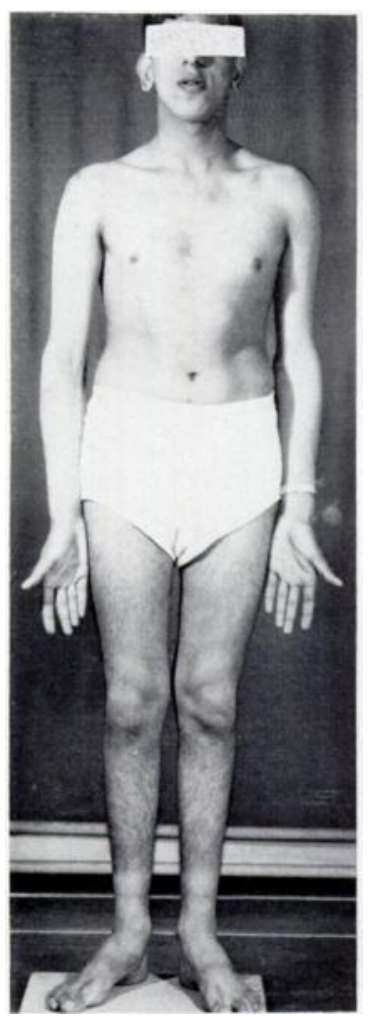

Fig. 2

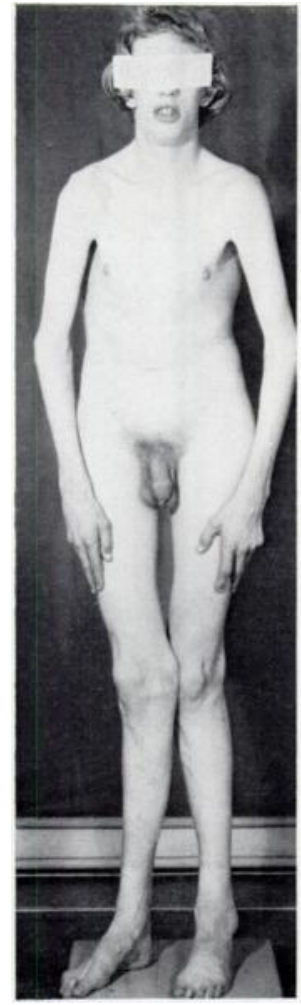

FIG. 3

Figure 2-Case 16. An Indian boy 15 years old with homocystinuria; he had bilateral lens dislocation, mild pes cavus and skeletal disproportion but was otherwise normal. Figure 3-Case 18. A patient aged 18 years, with homocystinuria; mentally retarded with bilateral lens dislocation and severe skeletal abnormalities.

identified clinically. In common with many other inherited diseases, therefore, in the less severe cases it can be diagnosed only by deciding which and how few of the several features of the disease must be present before the diagnosis is acceptable; this is arbitrary and probably excludes the most minor cases. In this study patients with Marfan's syndrome were included if more than one of the principal features known to be associated with the syndrome were present: dislocated lens, overgrowth of long bones with a disproportionately long lower body 
TABLE I

Patients With Homocystinuria-Body Measurements

\begin{tabular}{|c|c|c|c|c|c|c|c|c|}
\hline Patient & Sex & $\begin{array}{l}\text { Chrono- } \\
\text { logical age } \\
\text { (years) }\end{array}$ & $\begin{array}{c}\text { Weight } \\
\text { (kilograms) }\end{array}$ & $\begin{array}{c}\text { Height } \\
\text { (centimetres) }\end{array}$ & $\begin{array}{c}\text { Percentile } \\
\text { height }\end{array}$ & $\underset{\text { (centimetres) }}{\text { Span }}$ & $\begin{array}{c}\text { Crown-pubis } \\
\text { length } \\
\text { (centimetres) }\end{array}$ & $\begin{array}{c}\text { Pubis-heel } \\
\text { length } \\
\text { (centimetres) }\end{array}$ \\
\hline 1 & Male & $2 \frac{5}{12}$ & $15 \cdot 8$ & 95 & 90 & - & - & - \\
\hline 2 & Female & $3 \stackrel{3}{1:}$ & $18 \cdot 4$ & $98 \cdot 5$ & 93 & 100 & 53 & 48 \\
\hline 3 & Male & $6 \overline{1}$ & 26 & 121 & 96 & 121 & 63 & 61 \\
\hline 4 & Female & $7 \frac{2}{12}$ & $21 \cdot 7$ & 128 & 90 & 128 & 60 & 67 \\
\hline 5 & Male & $7+\frac{1}{12}$ & 24 & 125 & 78 & 123 & 61 & $66 \cdot 5$ \\
\hline 6 & Male & 78 & $26 \cdot 5$ & 138 & $>97$ & 144 & 61 & 76 \\
\hline 7 & Female & 79 & $23 \cdot 5$ & 126 & 65 & 125 & 57 & 64 \\
\hline 8 & Male & $10 \%$ & $34 \cdot 2$ & $146 \cdot 5$ & 85 & 148 & 68 & 78 \\
\hline 9 & Male & $11 \frac{8}{12}$ & $36 \cdot 5$ & 146 & 63 & - & 68 & 80 \\
\hline 10 & Male & 11190 & $30 \cdot 6$ & 147 & 65 & 152 & 65 & 84 \\
\hline 11 & Female & $12 \frac{2}{12}$ & $32 \cdot 8$ & 148 & 47 & 146 & 72 & 79 \\
\hline $12^{*}$ & Female & $13 \frac{2}{2}$ & 42 & 145 & $10^{*}$ & - & - & - \\
\hline 13 & Female & 1419 & $49 \cdot 7$ & 171 & 94 & 184 & 78 & 93 \\
\hline 14 & Female & $141 !$ & $46 \cdot 5$ & 165 & 85 & 165 & 75 & 91 \\
\hline 15 & Female & $15_{12}^{3}$ & $56 \cdot 7$ & 169 & 91 & 175 & 79 & 92 \\
\hline 16 & Male & 1518 & $66 \cdot 5$ & 179 & 90 & 189 & $85 \cdot 5$ & $94 \cdot 5$ \\
\hline 17 & Female & $16 \overline{3}$ & $56 \cdot 5$ & $170 \cdot 5$ & 91 & 172 & 79 & 93 \\
\hline 18 & Male & 18 是 & $63 \cdot 5$ & $190 \cdot 5$ & $>97$ & 193 & 82 & 111 \\
\hline 19 & Male & 20 & $68 \cdot 5$ & 178 & 75 & 187 & 81 & 97 \\
\hline 20 & Female & $21 \frac{3}{12}$ & 46 & 163 & 60 & 179 & 79 & 85 \\
\hline 21 & Female & 22 & $41 \cdot 5$ & 156 & 15 & 156 & 73 & 83 \\
\hline 22 & Male & 23 告 & 76 & 182 & 82 & 188 & 86 & 96 \\
\hline 23 & Male & $43_{12}^{4}$ & 46 & 163 & 3 & 179 & 77 & 87 \\
\hline
\end{tabular}

* Scoliosis affected the measurements in this patient.

segment, aneurysm of the aorta, scoliosis, excessive joint laxity with dislocation of joints, and a family history of similar disorders (but only when confirmed by medical evidence). Homocystinuria was excluded by the urinary cyanide-nitroprusside test.

The sixteen patients with Marfan's syndrome here described were found by a search of the disease index of the Departments of Orthopaedic Surgery and of Ophthalmology, University of Edinburgh, and from the Royal Hospital for Sick Children, Edinburgh. One further family is included by courtesy of Mr T. P. Mann, Western Infirmary, Glasgow.

\section{RESULTS}

HOMOCYSTINURIA

Skeletal and body measurements - The variability of the skeletal features is well shown in Figures 2 and 3 . The heights, weights and body proportion of the patients are shown in 
Table I. Thirteen of the twenty-two patients had heights above the 80th percentile for their age and only four were below the 50th percentile. One of these had severe scoliosis and her height of 145 centimetres (10th percentile) is therefore misleading. Two other patients were

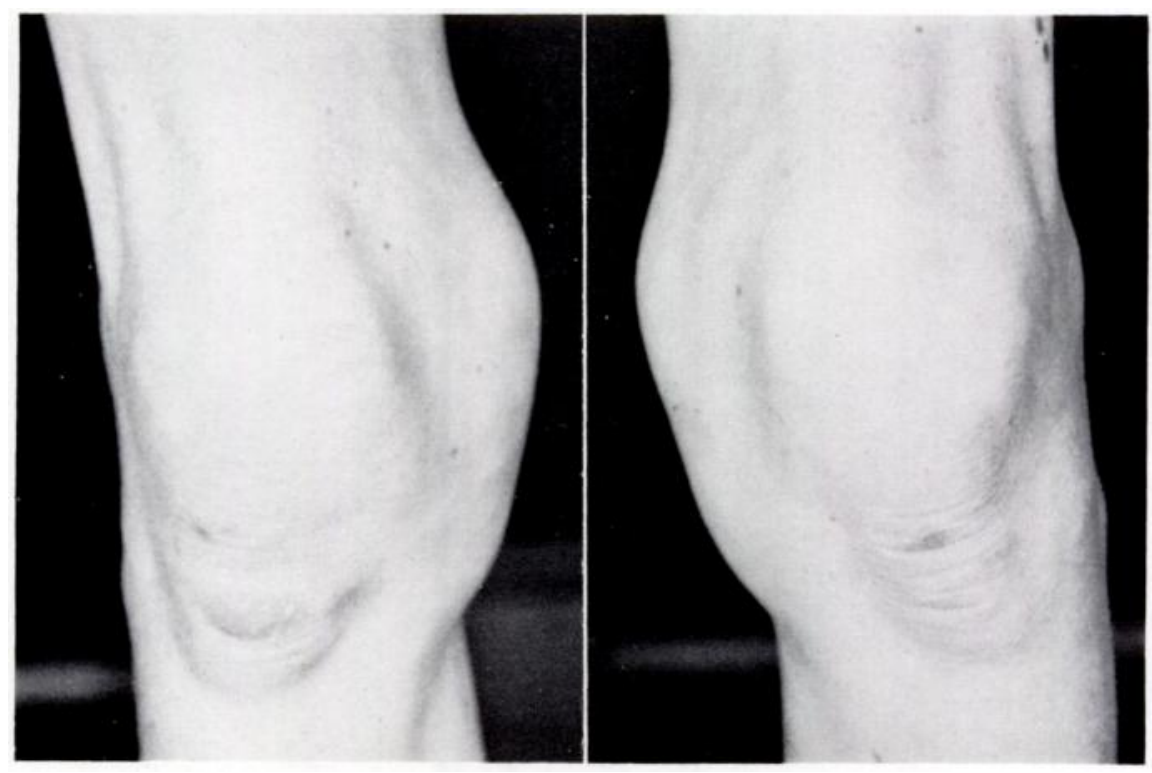

Fig. 4

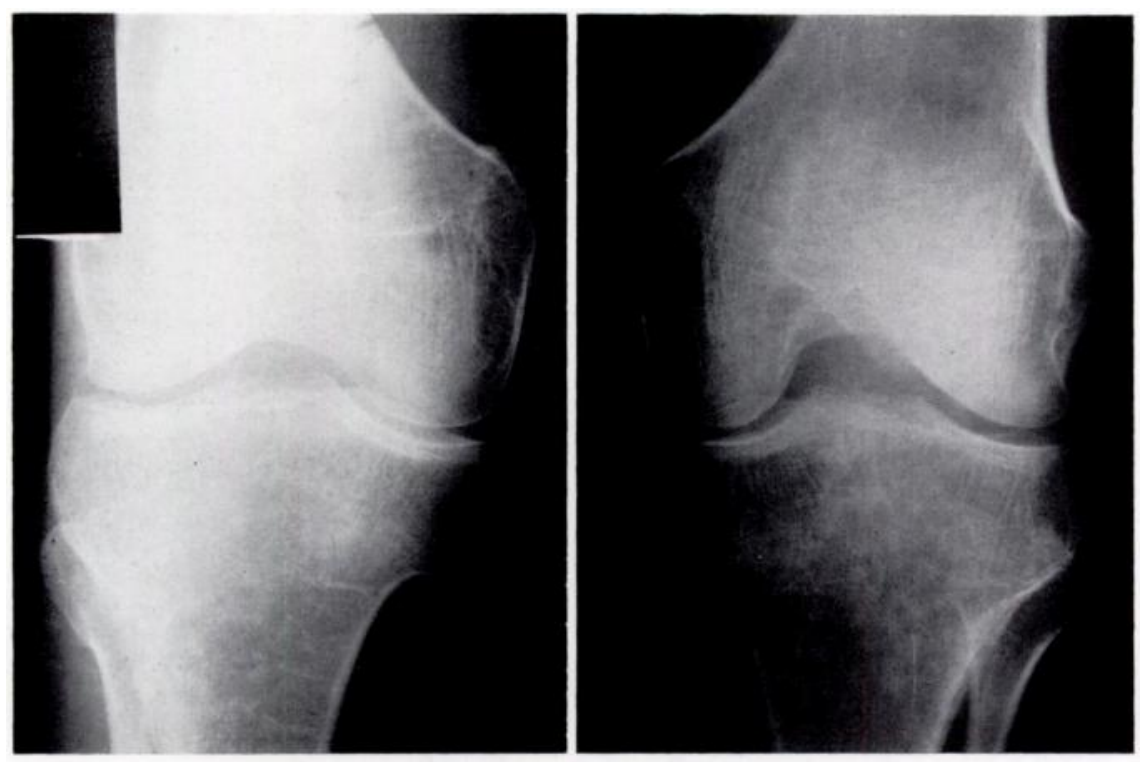

FIG. 5

Case 21-Female aged 22, with homocystinuria. Large abnormally shaped knees. Note that although the femoral metaphyses are normally modelled, the medial condyles of femora and tibiae are wide. Harris lines are prominent.

on the 15th and 3rd percentile for height--relatively short compared with the other patients. Neither had severe scoliosis to account for this. 


$$
\sqrt{17}
$$


The weight of most of the patients was correct for their height, but the widened metaphyses and epiphyses of long bones often gave them an awkward "bony" appearance (Figs. 4, 5, 11 and 12).

The ratio of the crown/pubis length to the pubis/heel length has been used as a measure of skeletal proportions (Fig. 6). One-third of the patients with homocystinuria had a ratio two standard deviations or more below the mean for their age and probably no patient had a ratio above the mean. Eight patients had a span which exceeded their height by more than 4 centimetres.

Skeletal age as an index of maturation was measured by the standard method of Greulich and Pyle (1959). These were all within a year of their chronological ages, but in one patient

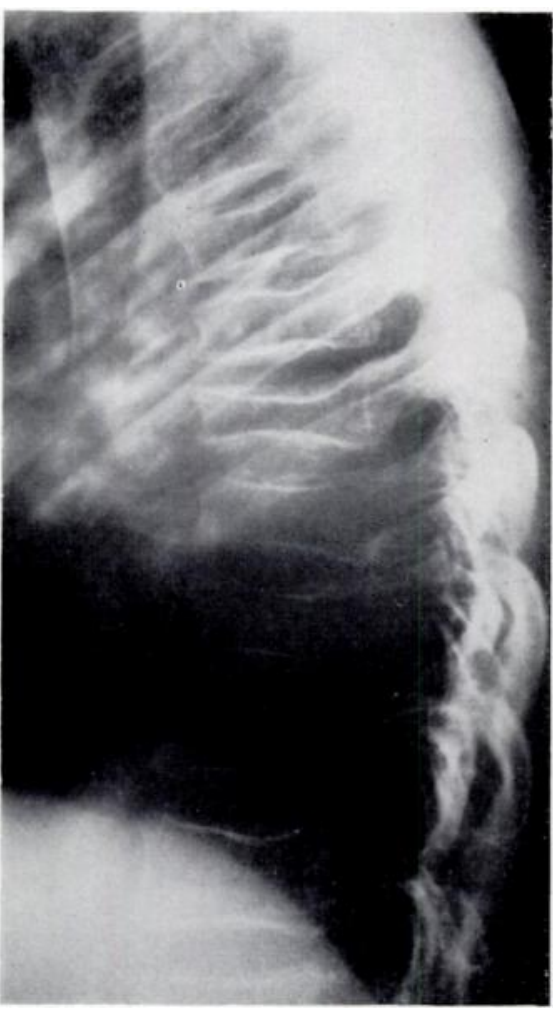

Fig. 9

Homocystinuria. Case 10-Boy aged 12 years. Lateral radiograph of spine showing osteoporotic collapse of eighth thoracic and first lumbar vertebrae. the ossification centre for the lunate bone was delayed and in six others those for the lunate, scaphoid, trapezium and trapezoid were delayed.

In all patients radiographs were available of the skull (lateral view), lumbar spine (antero-posterior and lateral views), chest, right forearm, hands and wrists, pelvis, hips and knees. Additional views of other parts of the skeleton were taken in some patients. The more important clinical and radiological findings are recorded in Table III.

Axial skeleton-A narrow highly arched palate was considered to be present in all except two patients, though this was a difficult sign to assess. Dental abnormalities were common, with considerable crowding of the teeth in the narrow upper jaw and protrusion of the incisors seen in lateral skull radiographs. There were no striking radiological abnormalities in the skull. Large sinuses have been commented upon by Brenton, Cusworth and Gaull (1965) and by other authors (Smith 1967, MacCarthy and Carey 1968). The resemblance of some of these radiological appearances to those in acromegaly were commented on by Brenton and colleagues (1965), but the pituitary fossa appeared of normal size in all patients.

Radiological changes in the spine were often striking. In part these were the changes of osteoporosis, the vertebrae appearing less dense than normal and biconcave. This anomaly was sometimes severe, even in young children, but the biconcave shape was not always typical of osteoporosis in that the concavity was rather posteriorly placed in the vertebral body (Fig. 7). A different appearance was seen in eleven patients, the vertebrae being flattened and widened but not markedly biconcave (Fig. 8). The posterior borders of the vertebrae were sometimes concave.

One patient had severe scoliosis, and a mild degree of curvature was present in eleven others. Osteoporotic collapse of the eighth thoracic and first lumbar vertebrae was seen in one patient (Fig. 9).

Sternal deformity, either pectus excavatum or carinatum, was found in three-quarters of the patients.

Appendicular skeleton-One of the important physical signs in homocystinuria was widening of the metaphyses and enlargement of the epiphyses of the long bones, most easily recognised at the knees and less obviously at the wrists, elbows and ankles. It was clinically obvious in 
the knees of eight patients and recognisable in four others. When not detectable on physical examination the widening was shown radiologically in some other patients (Figs. 10 to 12). Multiple Harris lines were frequently seen in the knees, as was abnormal metaphysial modelling. Two patients (Fig. 10) showed this in marked degree and milder changes were noticed in seven of the other eleven patients over the age of fifteen years. Eight patients had genu valgum. One of them still had an intermalleolar distance of 23.5 centimetres in spite of bilateral tibial osteotomies at the age of ten years. Milder degrees, 4-8 centimetres, were seen in the other seven.
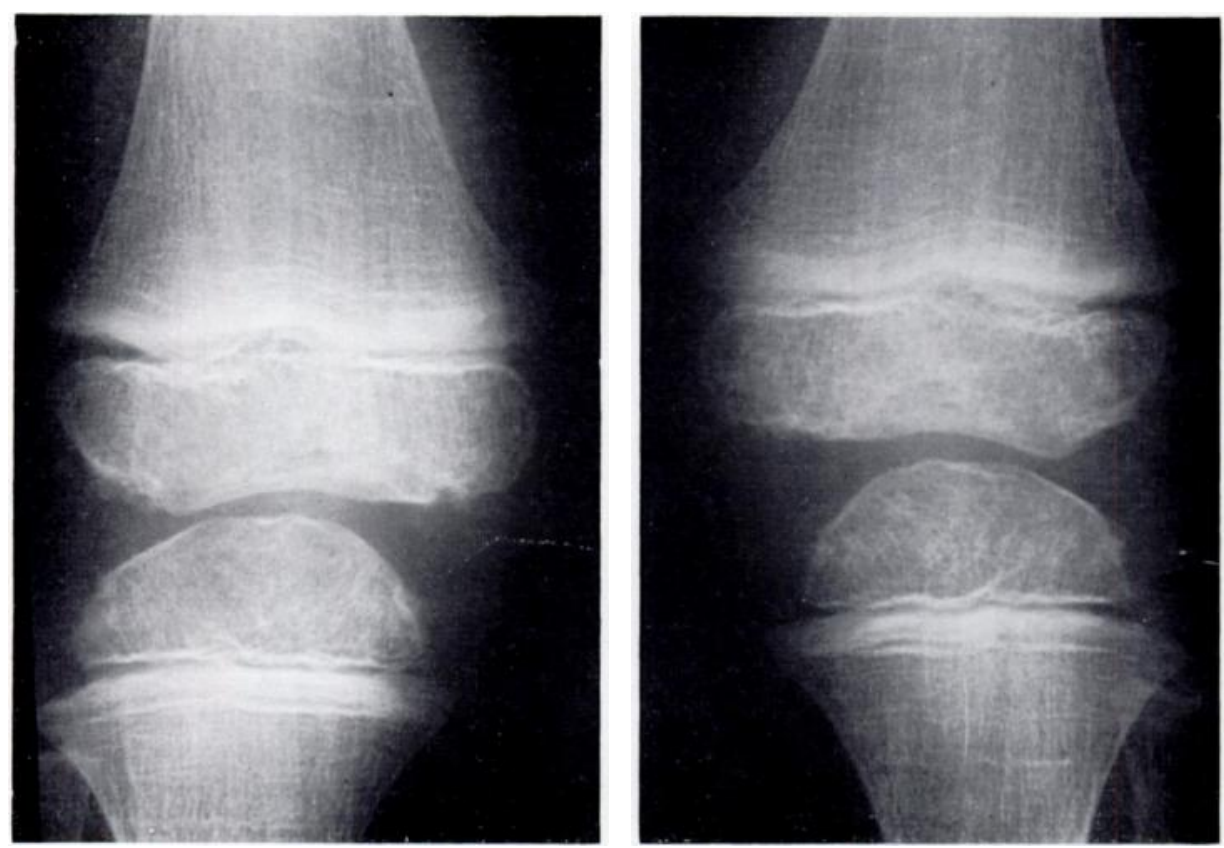

FIG. 10

Homocystinuria. Case 5-Boy aged 5 years. Radiograph of knees; the tibial epiphyses are tall. There are multiple Harris lines and dense metaphysial lines at the junction with the epiphysial plate.

The femoral head appeared large in ten patients and one had the typical appearances of Perthes' disease of the right hip. An abnormally long femoral neck and mild coxa valga were not uncommon. In six patients the femoral neck appeared abnormal in shape with a straight or convex superior margin instead of the usual concave shape (Fig. 13). Radiological appearances of the pelvis were possibly abnormal in some patients, the ilium appearing wider than normal just above the acetabulum in twelve patients (Fig. 14).

Abnormalities of the upper limbs were not so obvious. However, a large humeral head was noticed in some patients and a slight widening of the distal end of the ulna. One patient had a pathological fracture through a benign cystic lesion of the humerus. Large capitate and hamate bones were present in some patients and six patients showed the punctate ossification in the distal radial and ulnar epiphysial cartilage described by Morreels, Fletcher, Weilbaecher and Dorst (1968) (Fig. 15). This is also occasionally seen in normal children however.

Florid arachnodactyly as an obvious physical sign was not seen in any of the patients with homocystinuria, but six were judged clinically to have long fingers. The metacarpal index was used by Sinclair, Kitchin and Turner (1960) as a measure of arachnodactyly, and while it is probable that it has little diagnostic value it has been measured in each patient and the values 
compared to measurements made in normal subjects (Tables III, IV and below). Seven patients had finger contractures and fixed flexion deformities at the elbow with limited supination.

A number of patients had rather long toes. Twelve had a mild pes cavus deformity, one a severe flat foot, none had clawing of the toes.

Osteoporosis of the spine has been described above and sometimes other bones also were affected. Severe osteoporotic changes were found in four patients, moderate in seven, and the remaining twelve showed only mild osteoporotic changes or none at all.

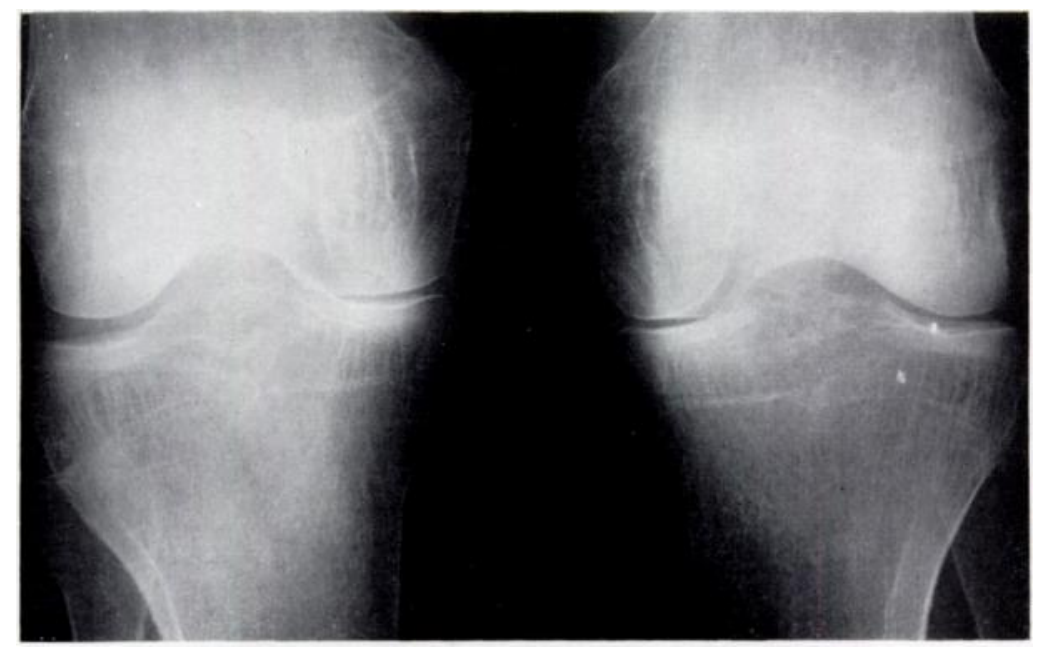

Fig. 11

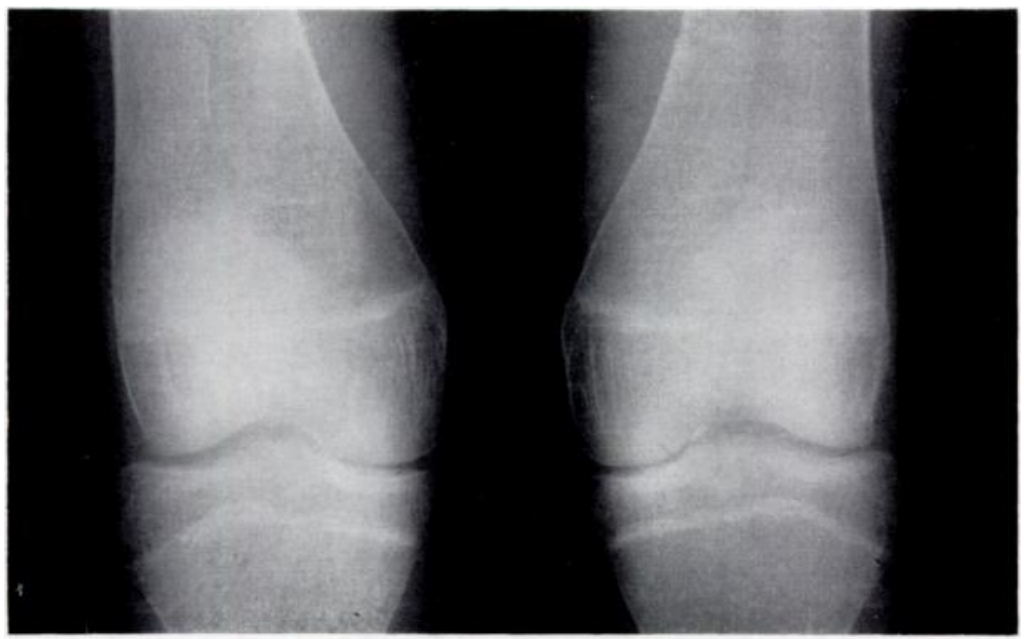

Fig. 12

Homocystinuria. Figure 11-Case 18. Figure 12-Case 13. Radiographs reproduced on the same scale and illustrating the enormous size of the knees in

Case_18. Note also the failure of modelling of the femoral metaphyses.

Non-skeletal features-The considerable variation in severity of the skeletal aspects of homocystinuria was also true in the non-skeletal features. The most important of these were mental retardation, lens dislocation and thrombosis (Table III). Thirteen of the twenty-two patients were mentally retarded, although the degree of retardation was not gross and only 


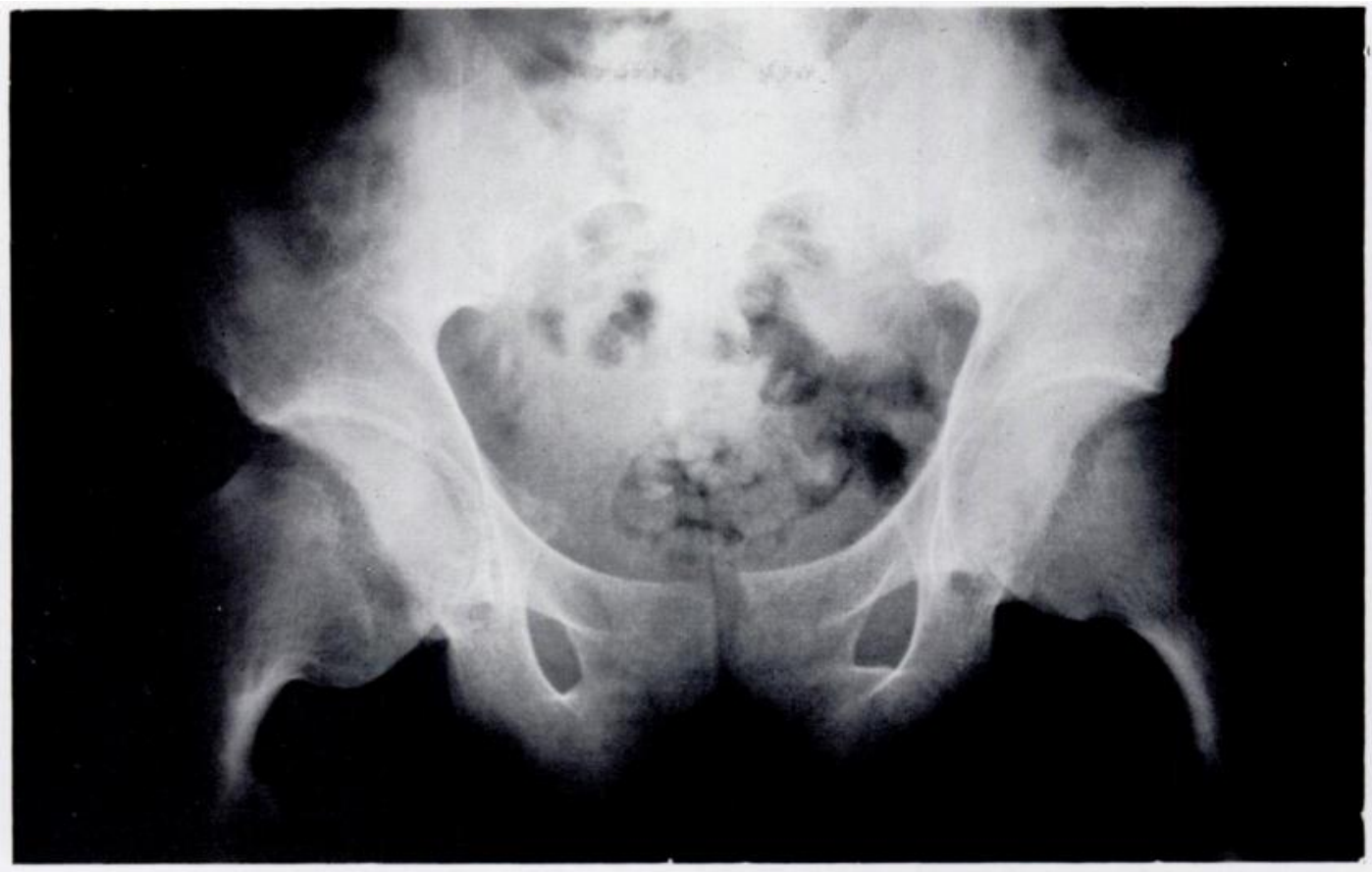

FiG. 13

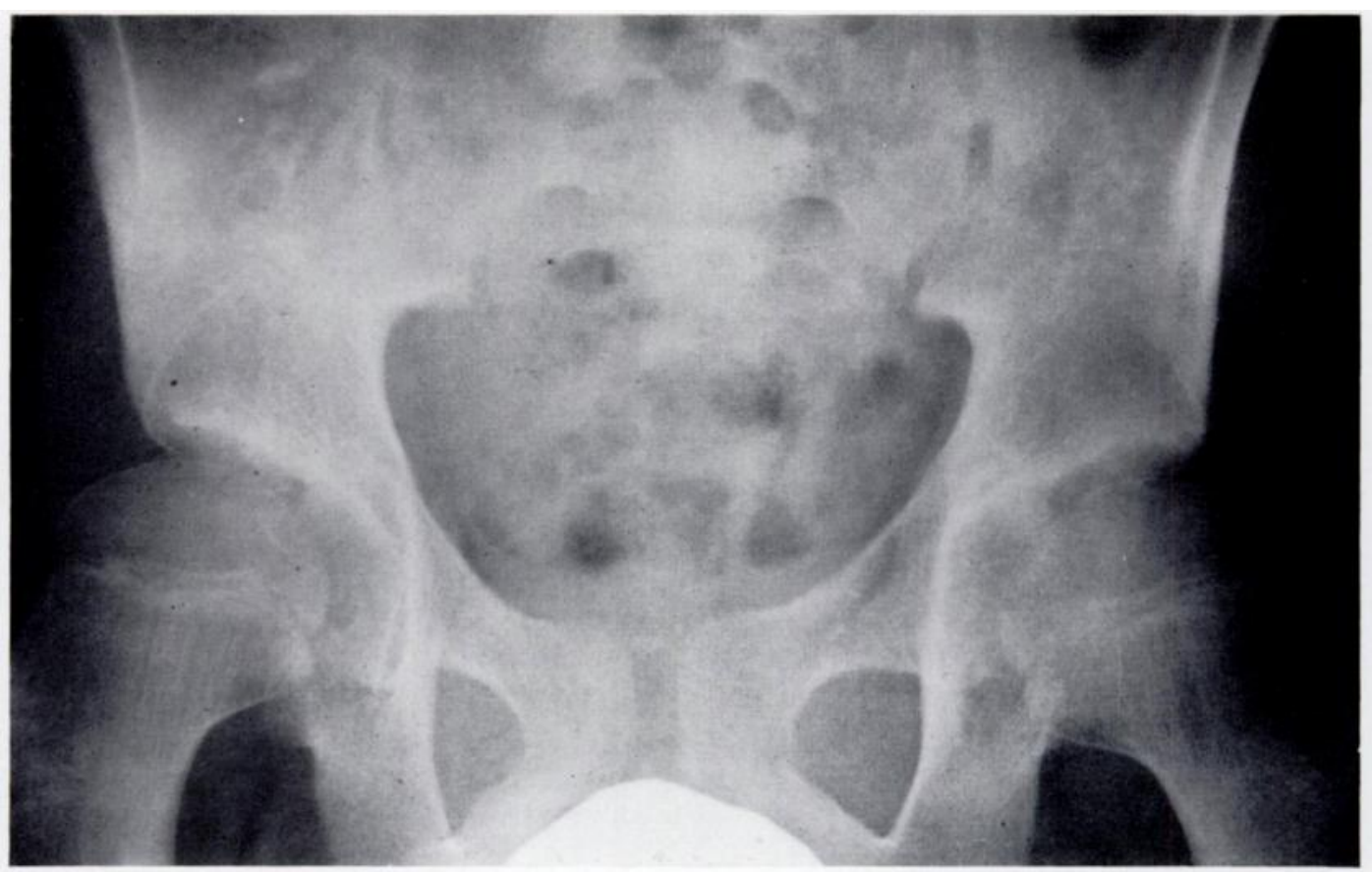

Fig. 14

Homocystinuria. Radiographs of pelvis and hips. Figure 13-Case 18. The femoral heads are huge and the necks convex along the upper border instead of the usual concave shape. Figure 14-Case 9. The same abnormalities are seen in lesser degree. Note the rather straight iliac bones and the wide appearance of the ilium above the acetabulum which, particularly on the right, is abnormally shallow. 


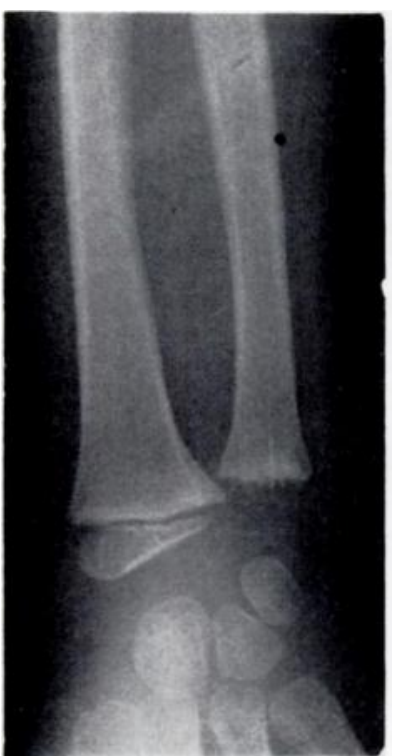

Fig. 15

Homocystinuria. Case 3Radiograph: note the punctate calcification in the ulnar epiphysial plate. one required permanent care in an institution. The patients with the most severe skeletal abnormalities were all mentally retarded.

Only two patients did not have lens dislocation but in each case a sibling had this complication, though without mental retardation or severe skeletal abnormalities. Of the remaining patients most had suffered lens dislocation before the age of ten years and often in early childhood. However, it occurred in three of them after the age of ten years and none of these had mental retardation or severe skeletal changes.

The most serious threat to life in homocystinuria probably arises from the tendency to thrombosis in arteries and veins (Gibson, Carson and Neill 1964). One patient died at the age of three and a half years from mesenteric thrombosis and intestinal infarction. Another had proven femoral vein thrombosis, and there was iliac or inferior vena caval occlusion in three others. In two patients corrective osteotomy for genu valgum and incorporation of the legs in plaster may have been the precipitating cause.

Another non-skeletal feature of homocystinuria, the malar flush, occurred in some patients but varied from day to day even in the same patient.

\section{MARFAN'S SYNDROME}

Skeletal and body measurements-Age, sex, height and body proportions of the patients are shown in Table II. Seven patients were above the 80th percentile for height and the figures for some of the shorter ones are misleading because of severe scoliosis. The crown/pubis heel ratios are illustrated in Figure 6. In eight patients the span exceeded the height by more than four centimetres. These various measurements confirm the well known observation that patients with Marfan's syndrome are taller than average and have long arms and legs in relation to trunk length (Fig. 16). The principal clinical and radiological features are shownin Table III.

Axial skeleton-Four patients showed narrow high-arched palates and five sternal and chest deformities similar to homocystinuria.

In contrast to homocystinuria where severe scoliosis is uncommon, nine of the Marfan's syndrome patients showed scoliosis and in many it was very severe, indeed the most severe skeletal deformity. Radiographs in Figures 17 and 18 show a sister and brother with scoliosis. The girl has many typical features of Marfan's syndrome; her brother, a patient in the scoliosis clinic, was discovered to have the disease only after his sister was seen. In him the evidence of Marfan's syndrome was very slight; until this was recognised he was thought to have infantile idiopathic scoliosis. The signs of Marfan's syndrome have increased with age.

FIG. 16

Patient aged 20 years with Marfan's syndrome. He has lens dislocation, skeletal disproportion, pigeon chest and severe scoliosis.

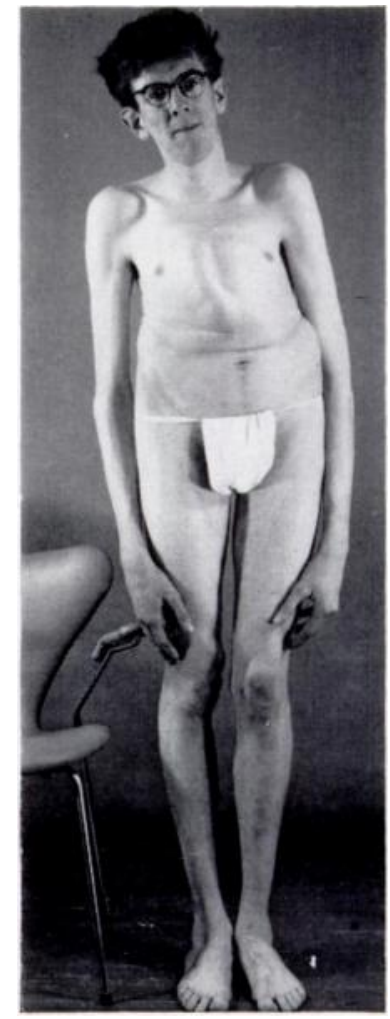

FIG. 16 
TABLE II

Patients with Marfan's Syndrome-Body Measurements

\begin{tabular}{|c|c|c|c|c|c|c|c|}
\hline Patient & Sex & $\begin{array}{c}\text { Chronological } \\
\text { age } \\
\text { (years) }\end{array}$ & $\begin{array}{c}\text { Height } \\
\text { (centimetres) }\end{array}$ & $\begin{array}{c}\text { Percentile } \\
\text { height }\end{array}$ & $\begin{array}{c}\text { Span } \\
\text { (centimetres) }\end{array}$ & $\begin{array}{c}\text { Crown-pubis } \\
\text { length } \\
\text { (centimetres) }\end{array}$ & $\begin{array}{c}\text { Pubis-heel } \\
\text { length } \\
\text { (centimetres) }\end{array}$ \\
\hline 1 & Female & $5 \frac{7}{12}$ & $111 \cdot 8$ & 60 & $116 \cdot 8$ & 55.9 & 55.9 \\
\hline 2 & Female & 6 & $118 \cdot 1$ & 80 & $122 \cdot 6$ & $58 \cdot 4$ & $57 \cdot 2$ \\
\hline 3 & Female & 7 占 & $121 \cdot 3$ & 50 & $115 \cdot 6$ & $57 \cdot 2$ & $64 \cdot 8$ \\
\hline 4 & Male & 8 监 & - & - & - & 65 & 68 \\
\hline 5 & Female & $8 \stackrel{2}{12}$ & $139 \cdot 7$ & $>97$ & $144 \cdot 8$ & $69 \cdot 9$ & $73 \cdot 7$ \\
\hline 6 & Female & $9 \underset{12}{6}$ & $131 \cdot 4$ & 45 & 128.9 & 66 & $67 \cdot 3$ \\
\hline 7 & Female & 109 & $148 \cdot 6$ & 90 & $154 \cdot 3$ & $71 \cdot 1$ & $78 \cdot 4$ \\
\hline $8^{*}$ & Male & $12 \frac{8}{12}$ & 153 & 75 & 174 & $72 \cdot 4$ & 80 \\
\hline $9^{*}$ & Female & 143 & - & - & - & 一 & - \\
\hline 10 & Female & $15 \mathrm{H}$ & 175.9 & $>97$ & $186 \cdot 7$ & $83 \cdot 8$ & $91 \cdot 4$ \\
\hline 11 & Male & 18 年 & $191 \cdot 8$ & $>97$ & $195 \cdot 6$ & $86 \cdot 3$ & $101 \cdot 6$ \\
\hline $12^{*}$ & Male & $19 \mathrm{~K}$ & $172 \cdot 7$ & 35 & 193 & - & - \\
\hline $13^{*}$ & Male & $20 \%$ & $176 \cdot 5$ & 55 & - & - & - \\
\hline $14^{*}$ & Male & 223 & 183 & 82 & $190 \cdot 5$ & $83 \cdot 8$ & $99 \cdot 1$ \\
\hline 15 & Female & $24 \frac{2}{12}$ & $179 \cdot 1$ & $>97$ & 181 & $86 \cdot 4$ & $95 \cdot 2$ \\
\hline 16 & Female & 3111 & $159 \cdot 4$ & 30 & $163 \cdot 2$ & $78 \cdot 4$ & $83 \cdot 8$ \\
\hline
\end{tabular}

* Scoliosis affected the measurements in these patients.

The scoliosis is usually an irregular thoraco-lumbar curve (Fig. 19) or a double primary curve, and the prognosis must in general be regarded as serious.

No patient with Marfan's syndrome showed the osteoporotic biconcave vertebrae or flat elongated vertebrae of homocystinuria. Osteoporosis was never seen, though in some radiographs the trabecular pattern was finely marked in delicate tracing, a possible feature of early osteoporosis. Three patients showed very tall lumbar vertebrae (Fig. 20), in remarkable contrast to the flat widened vertebrae of homocystinuria.

Appendicular skeleton--The long bones were slender and the wide "knobbly" metaphyses and epiphyses of homocystinuria were not seen. Moulding of the metaphysis was not always complete (Fig. 21), but the irregularity shown in severe homocystinuria was not seen.

One elbow joint showed lateral displacement of the head of radius with disintegration of the lateral condyle (Fig. 22). Later the whole joint became "buttressed" medially and laterally (Fig. 23). We have never seen similar changes from any other cause.

The ulnar distal epiphyses never showed the stippling occasionally seen in homocystinuria.

Arachnodactyly, long spidery fingers and feet, the feature which first gave the syndrome a name, was common and ten patients showed obvious clinical evidence of this. The radiographs of hands and feet (Figs. 24 and 25) show the long slender metacarpals, metatarsals and phalanges.

Metacarpal index-This was measured in a control group of 334 individuals, the radiographs being obtained from the hand clinic of the Department of Orthopaedic Surgery, Edinburgh. In all cases used the radiographs were taken after injury (Table IV). The mean value was less

VOL. 54 B, NO. 2, MAY 1972 

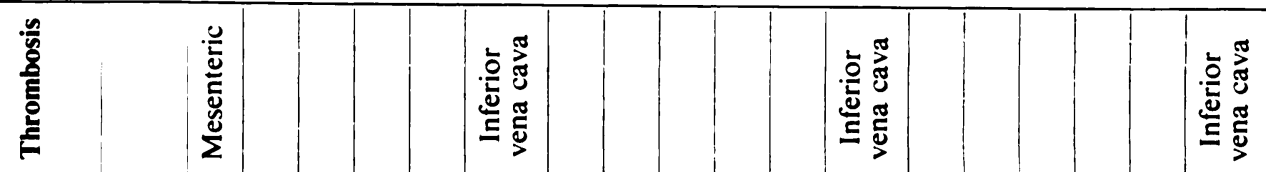

흥

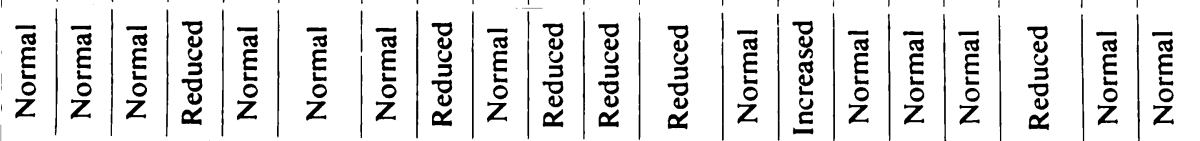

这总

这密

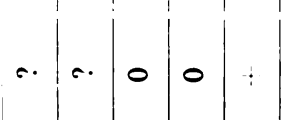

害

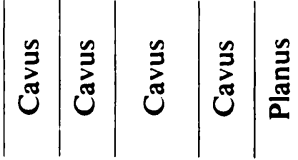

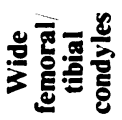

产

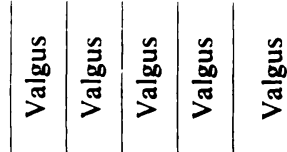

$10 \mid$\begin{tabular}{l|l|l|l|l|l|} 
& 0 & 0 & 0 & 0
\end{tabular}

¿

$\vdots$

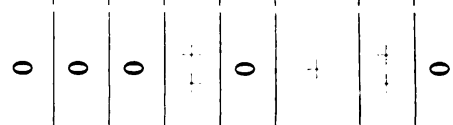

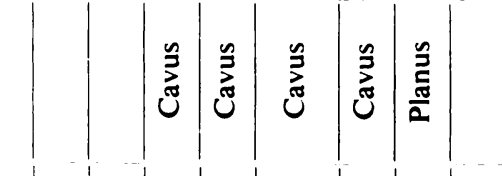

竞

仓̋

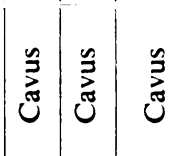
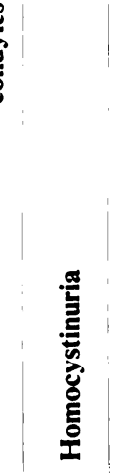

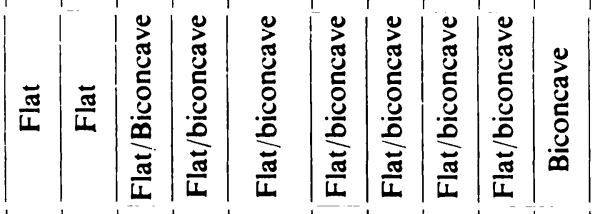

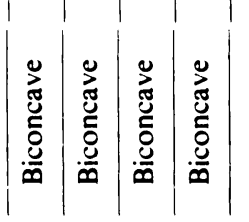

\begin{tabular}{c|}
$\therefore$ \\
$\therefore$
\end{tabular}

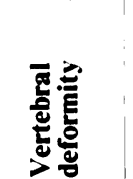

$\frac{\frac{n}{6}}{\bar{c}}$

选育

竞

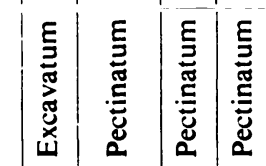

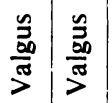

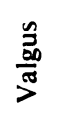

$\left|\begin{array}{c}\vdots \\ \vdots \\ \frac{5}{5} \\ \frac{50}{7}\end{array}\right|$

它总总

造

产离高

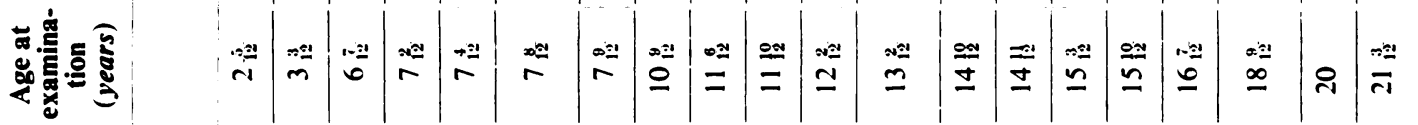

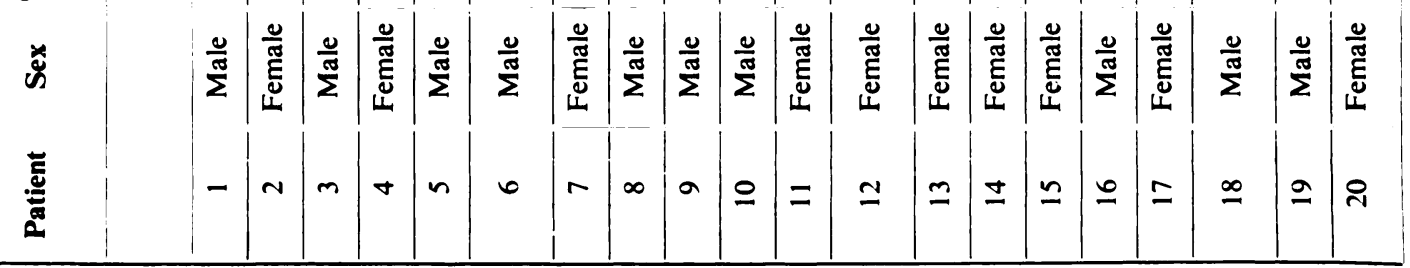




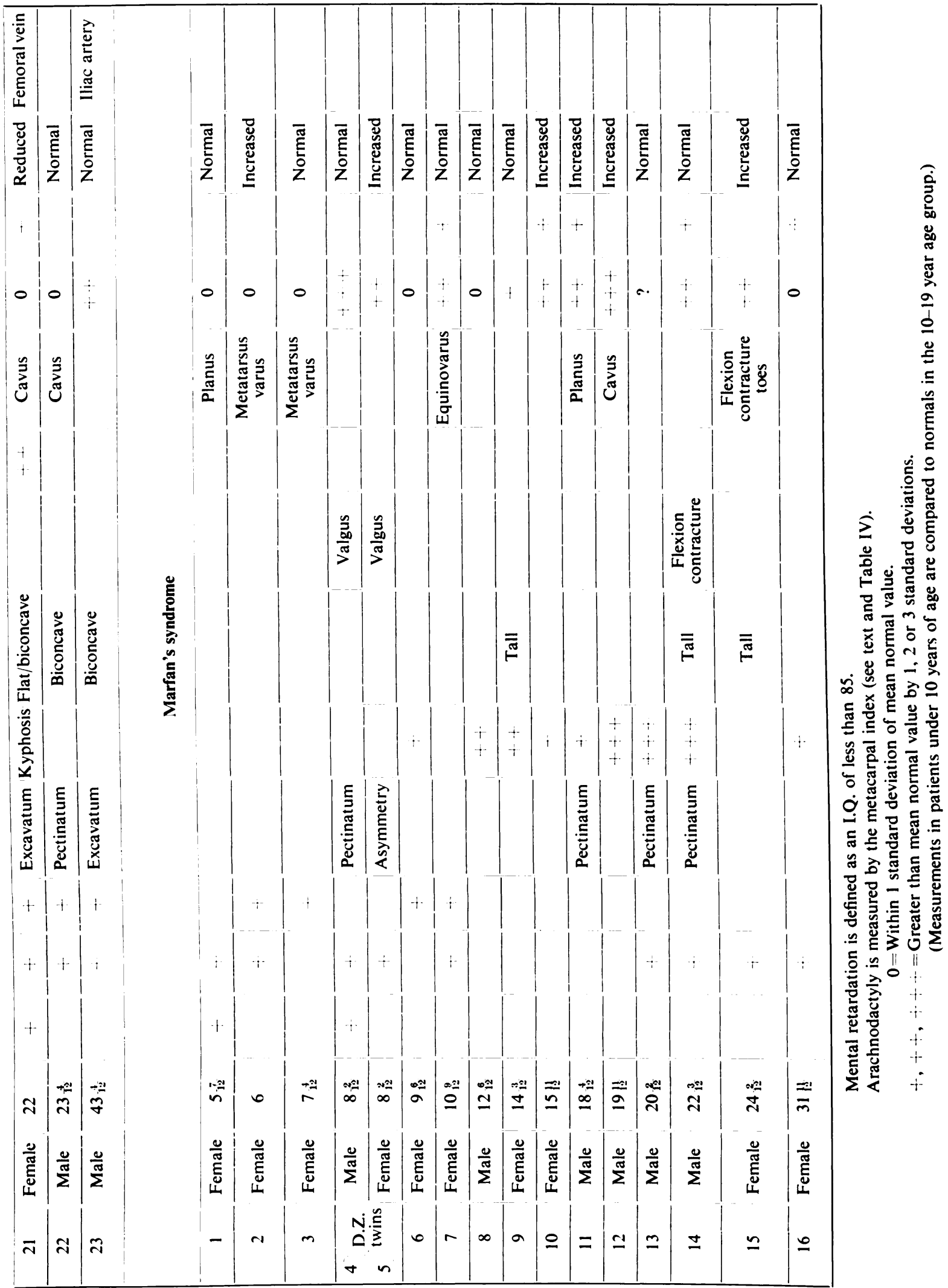




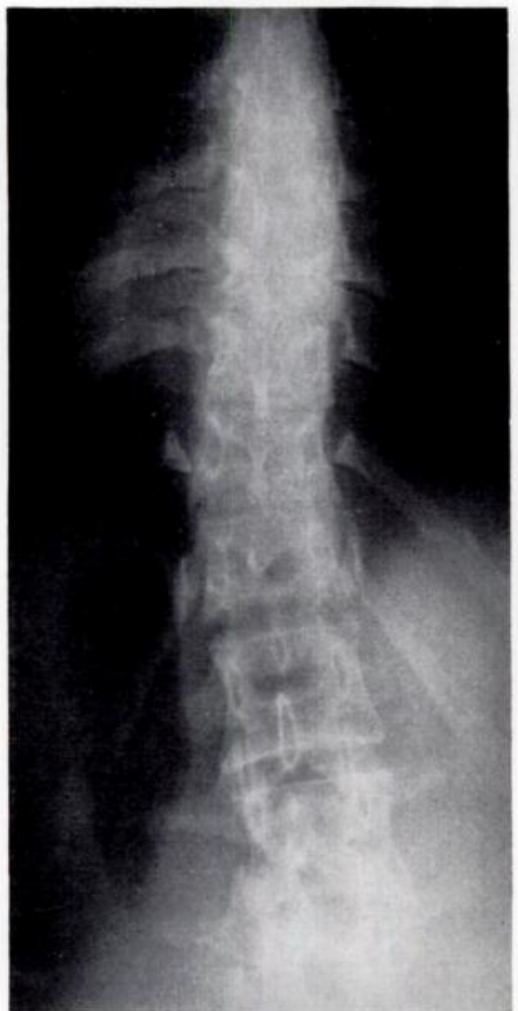

Fig. 17

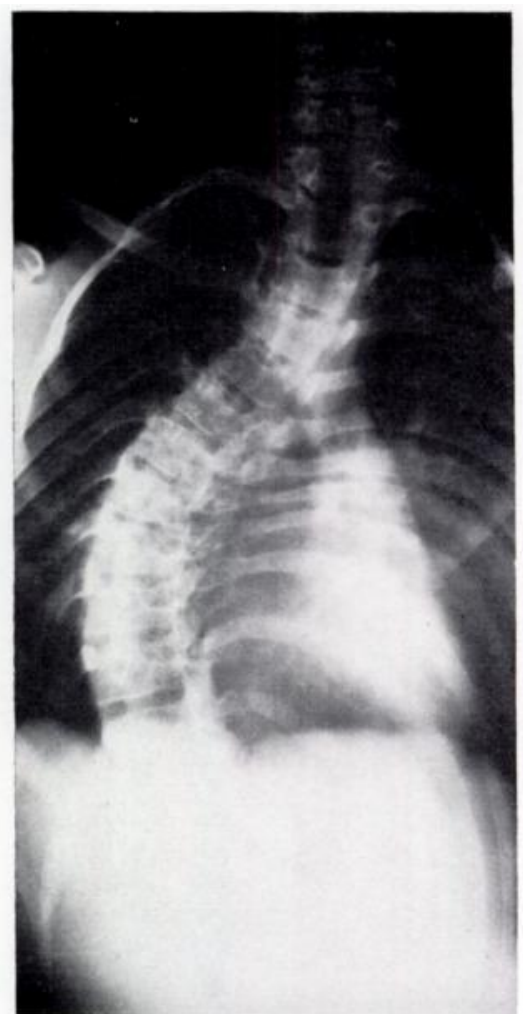

FIG. 18

Radiographs of spine in a sister and brother both with Marfan's syndrome and scoliosis.

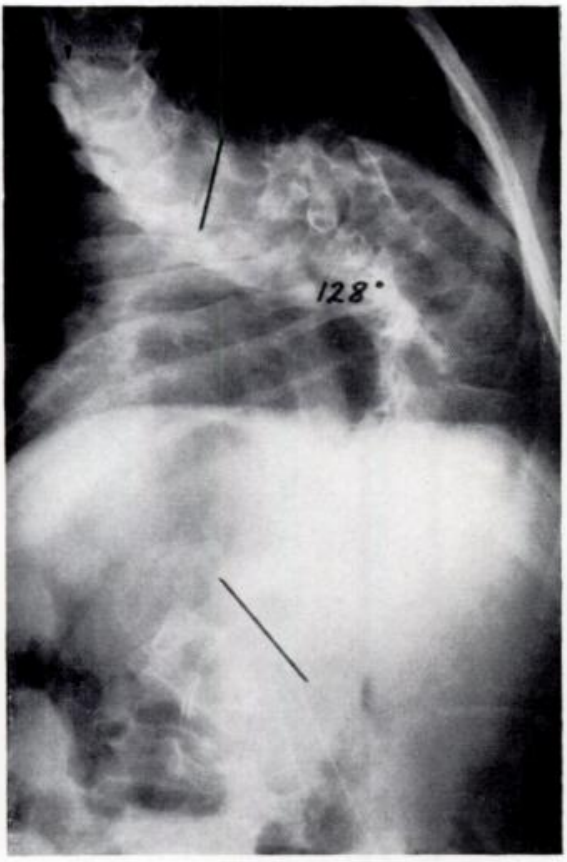

Fig. 19

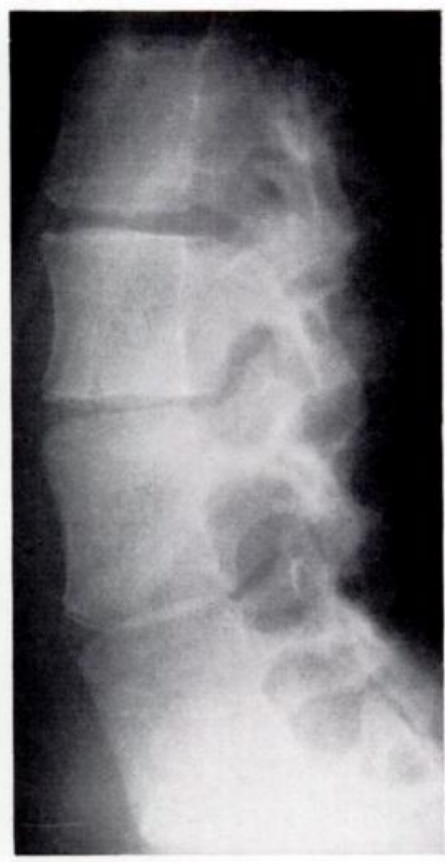

Fig. 20

Figure 19-Radiograph of spine of patient aged 14 years with Marfan's syndrome and severe scoliosis. Figure 20-Radiograph of spine of patient aged 14 years illustrating the abnormally tall vertebrae sometimes seen in Marfan's syndrome. 
in males than in females, and there was a slight reduction with increasing age. Measurement of the metacarpal index in patients with Marfan's syndrome showed a value one or more standard deviations over the expected mean in twelve of the sixteen cases (Table III).

TABLE IV

Metacarpal IndeX in 334 Normal Subjects

\begin{tabular}{|c|c|c|c|c|c|c|}
\hline \multicolumn{7}{|c|}{ Males } \\
\hline Age (years) & $10-19$ & $20-29$ & $30-39$ & $40-49$ & $50-59$ & $>60$ \\
\hline Number of individuals & 56 & 68 & 39 & 46 & 33 & 21 \\
\hline Metacarpal index & $\begin{array}{r}7 \cdot 22 \\
\therefore \quad 0.48\end{array}$ & $\begin{array}{r}7 \cdot 19 \\
+0.50\end{array}$ & $\begin{array}{r}7.01 \\
+0.48\end{array}$ & $\begin{array}{r}6.88 \\
\pm 0.44\end{array}$ & $\begin{array}{r}6.82 \\
+0.45\end{array}$ & $\begin{array}{r}6.98 \\
-\quad 0.55\end{array}$ \\
\hline \multicolumn{7}{|c|}{ Total number 263. Mean $7.05 \pm 0.50$} \\
\hline \multicolumn{7}{|c|}{ Females } \\
\hline Age (years) & $10-19$ & $20-29$ & $30-39$ & $40-49$ & $50-59$ & $>60$ \\
\hline Number of individuals & 18 & 9 & 7 & 12 & 13 & 12 \\
\hline Metacarpal index & $\begin{array}{r}7.74 \\
+0.56\end{array}$ & $\begin{array}{r}7.23 \\
+0.52\end{array}$ & $\begin{array}{r}7.87 \\
+0.96\end{array}$ & $\begin{array}{r}7.17 \\
+0.65\end{array}$ & $\begin{array}{r}7.55 \\
\therefore \quad 0.32\end{array}$ & $\begin{array}{r}7.32 \\
+\quad 0.74\end{array}$ \\
\hline \multicolumn{7}{|c|}{ Total number 71 . Mean $7.48 \div 0.65$} \\
\hline
\end{tabular}

The pelvis occasionally showed a vertical iliac wing without the characteristic flaring out, and the cavity of the pelvis seemed large in some patients (Fig. 26). A feature seen in all but one of the sixteen cases was coxa valga, often extreme (Fig. 27). A "tipped" femoral head (Murray and Duncan 1971) was common.

The feet were often long and flat. Only one showed pes cavus. Adduction of the forefoot, metatarsus varus, has been recognised as characteristic of Marfan's syndrome.

Non-skeletal features-Joint laxity was a feature of this disease in six cases and one of the patients had also congenital dislocation of an acromio-clavicular joint. Finger joint deformities with a 90-degree flexion contracture at the proximal interphalangeal joint occurred in five. Although seen in other conditions, its presence should cause Marfan's syndrome to be seriously considered even in the young (Fig. 28). Congenital palmar shortening, a condition in which the soft tissue of the flexor aspect of palms and fingers is short, was seen. It was also noted that finger contracture with undue mobility of other joints could occur in the same individual.

Dislocation of the lens was common in Marfan's syndrome, occurring in nine of the sixteen patients. Dislocation of the lens must always be regarded as a possible sign of one of these two diseases, but it should be noted that there is also probably more than one inherited anomaly of lens dislocation occurring as an isolated lesion (McKusick 1968). Other eye changes in Marfan's syndrome included strabismus, seen in three patients, and severe myopia in one patient.

Visceral hernia has been a remarkable feature in some series, though not in this one. However, three affected uncles of one of the index patients all died at the age of twenty-nine from complications of abdominal hernia after numerous operations for multiple herniae.

No patient in this series had aortic arch dilation or dissecting aneurysm due to a defect in the arterial media, though the fathers of two of them are thought to have died from this. 

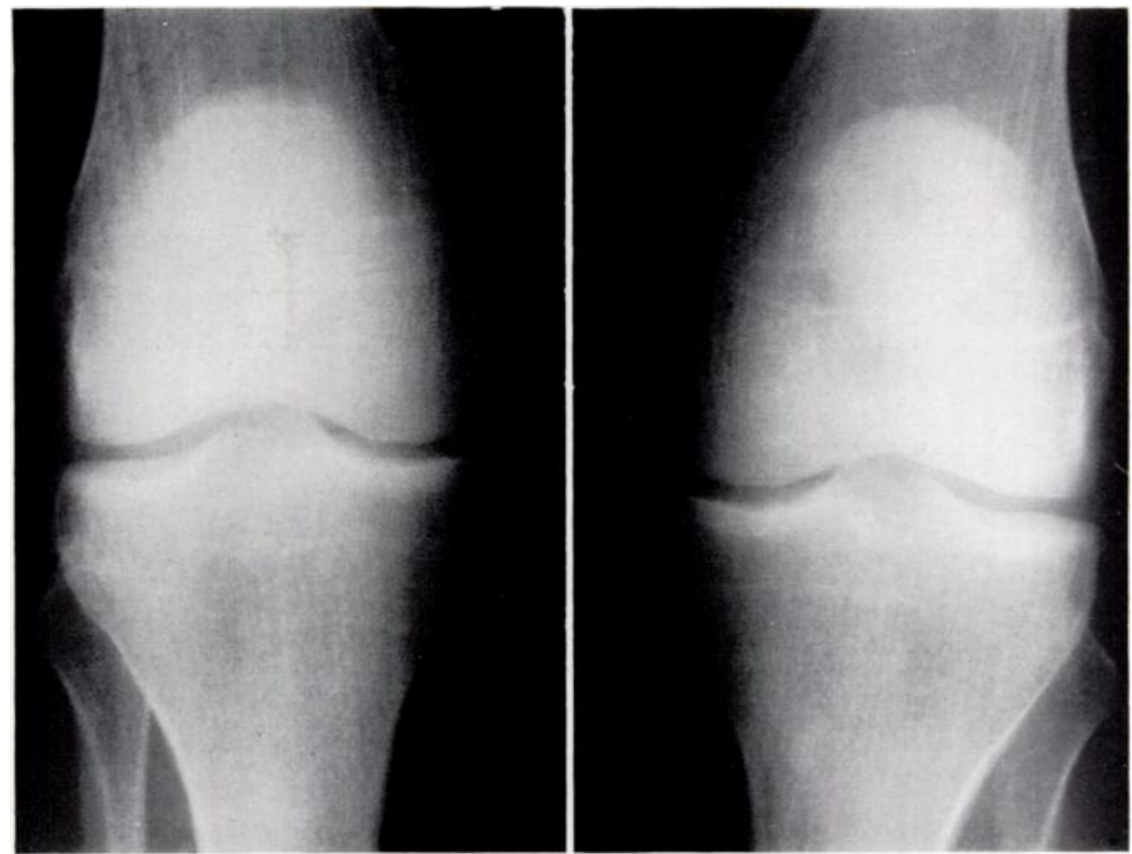

Fig. 21

Radiograph of knees of patient aged 18 years with Marfan's syndrome. There is some failure in the moulding of the metaphyses, but the changes are not so obvious as in homocystinuria.

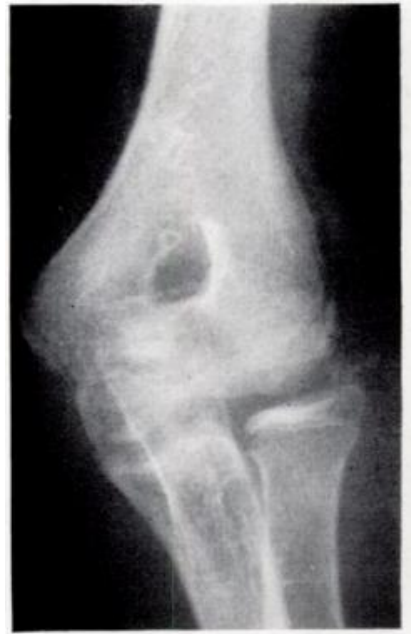

Fig. 22

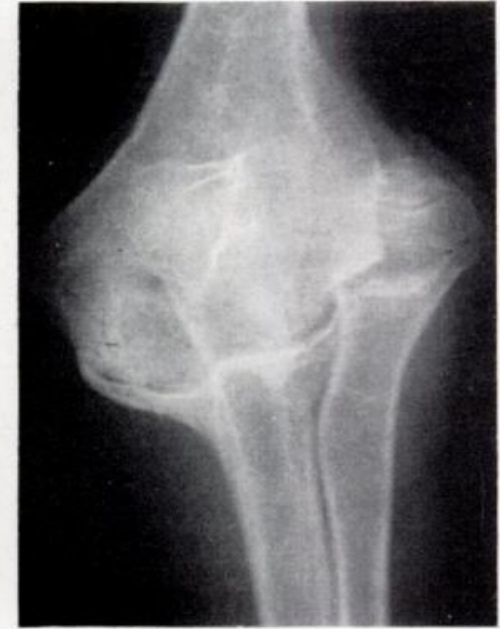

FIG. 23

Marfan's syndrome. Radiographs of the elbow taken at the ages of 10 and 14 years. There was no history of injury sufficient to account for the disordered joint, and the "buttressing" seen in the later radiograph is a bizarre feature. 
These serious arterial complications appear to occur at a later age than the index patients in this series, all of whom but one were under the age of twenty-five years. It seems from the

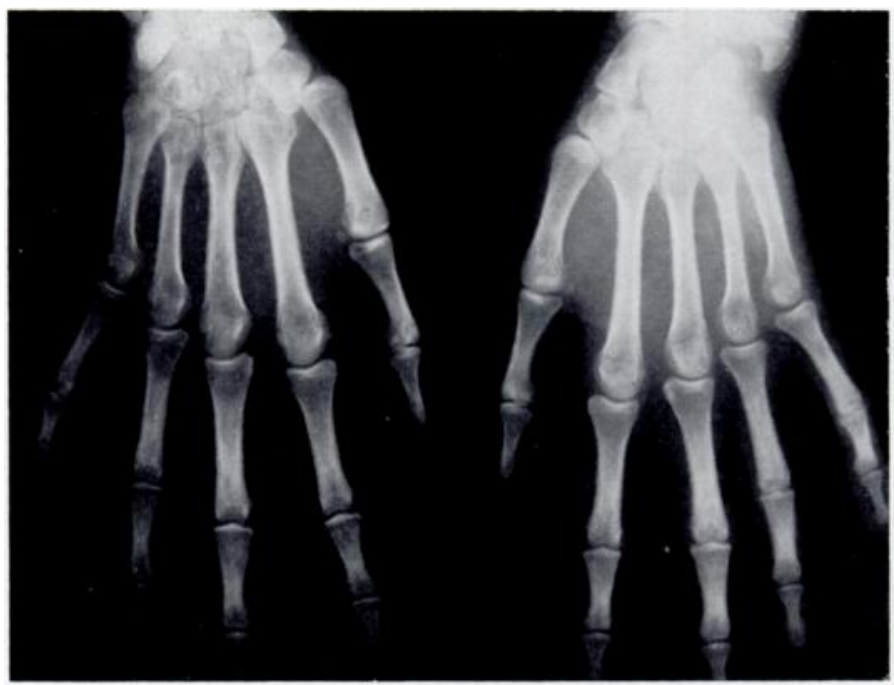

FIG. 24

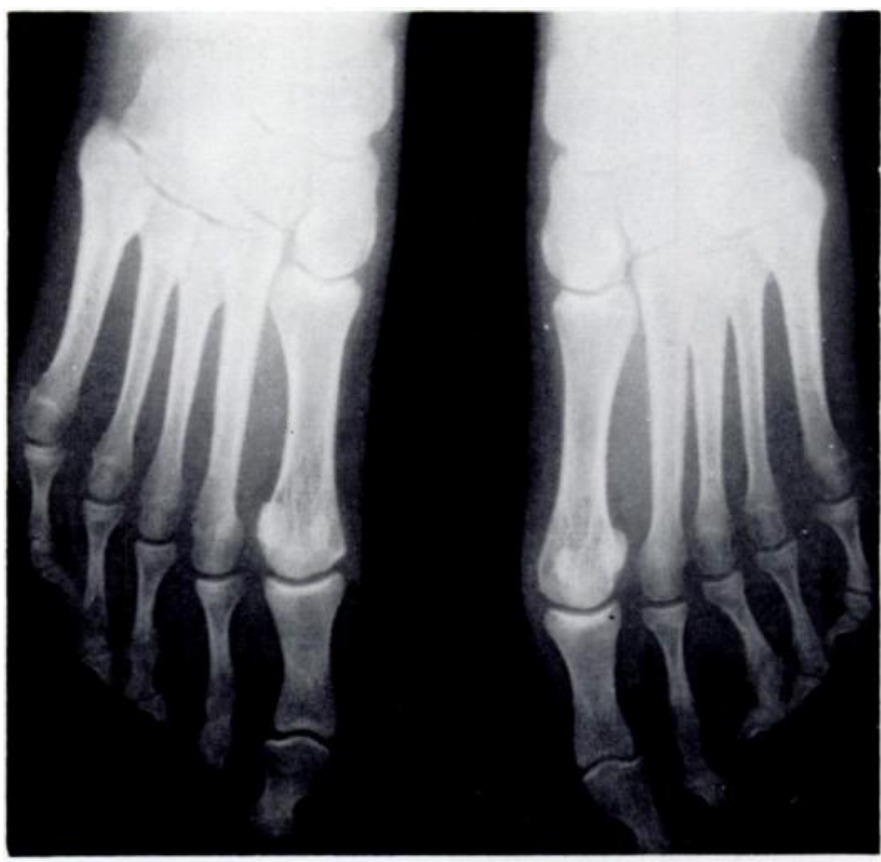

Fig. 25

Marfan's syndrome. Radiographs of hands and feet. Note the long slender metacarpals, metatarsals and phalanges.

literature (McKusick 1966) that death from this is the common fate of many middle-aged patients. Death from thrombosis as seen in homocystinuria is not a feature of Marfan's syndrome.

VOL. 54 B, NO. 2, MAY 1972

$\mathrm{F}$ 


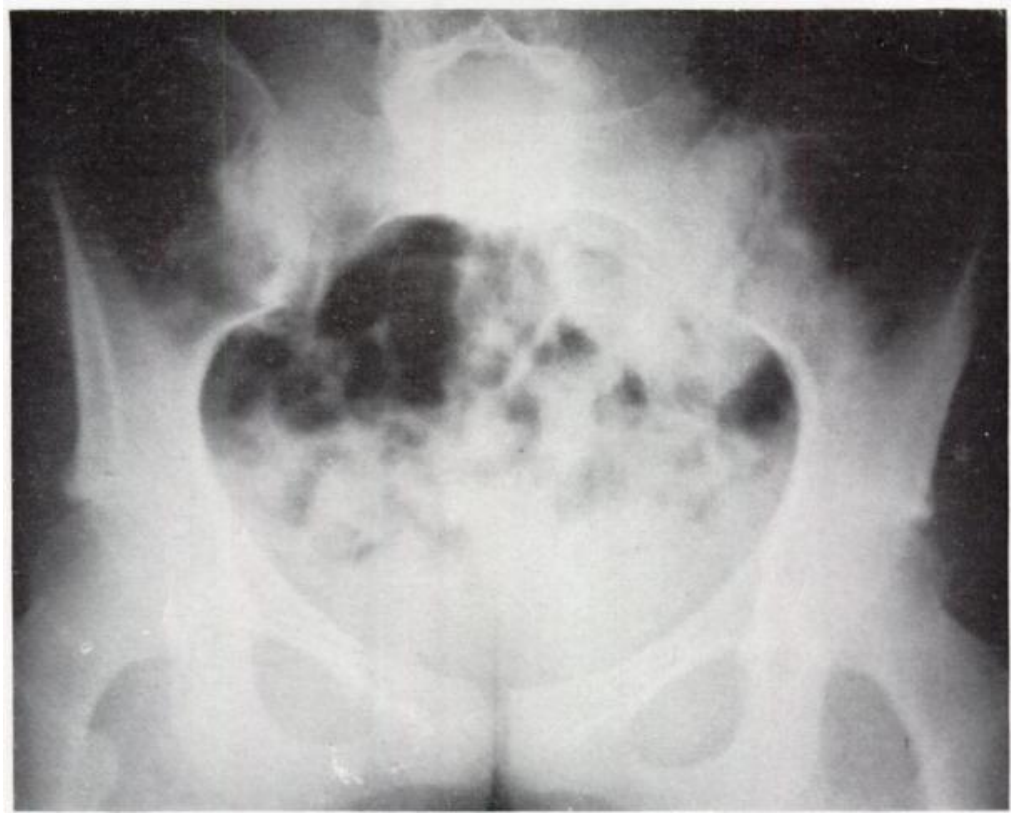

Fig. 26

Marfan's syndrome. Patient aged 15 years. The vertical ilium and wide pelvic cavity are well shown.

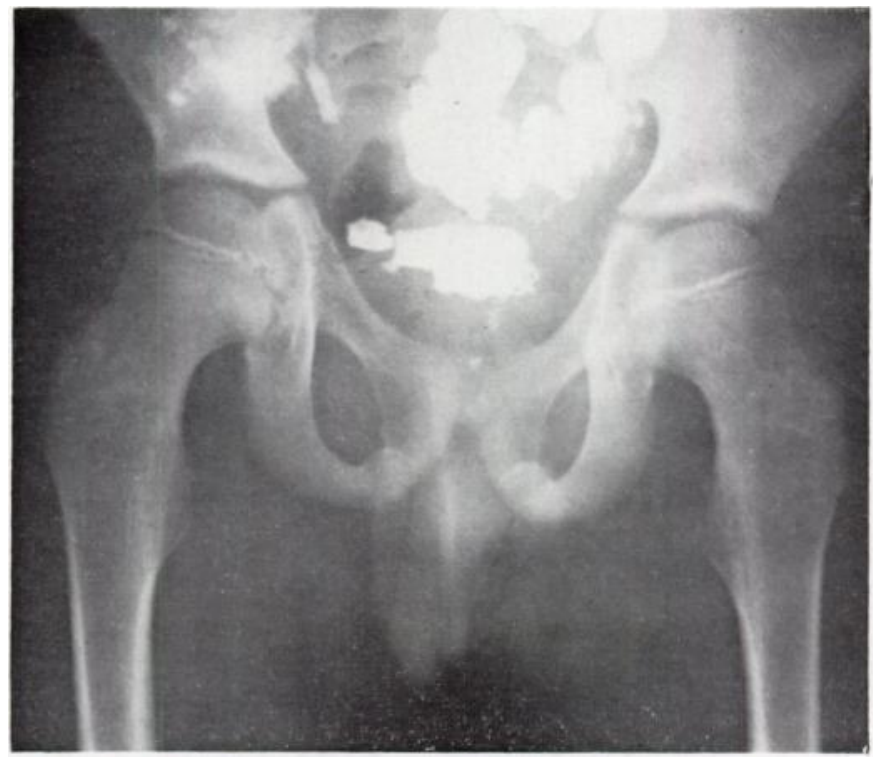

Fig. 27

Patient aged 8 years, one of dizygotic twins both with dislocated lenses and other features of Marfan's syndrome. The radiograph illustrates the coxa valga seen in all but one of the series. 


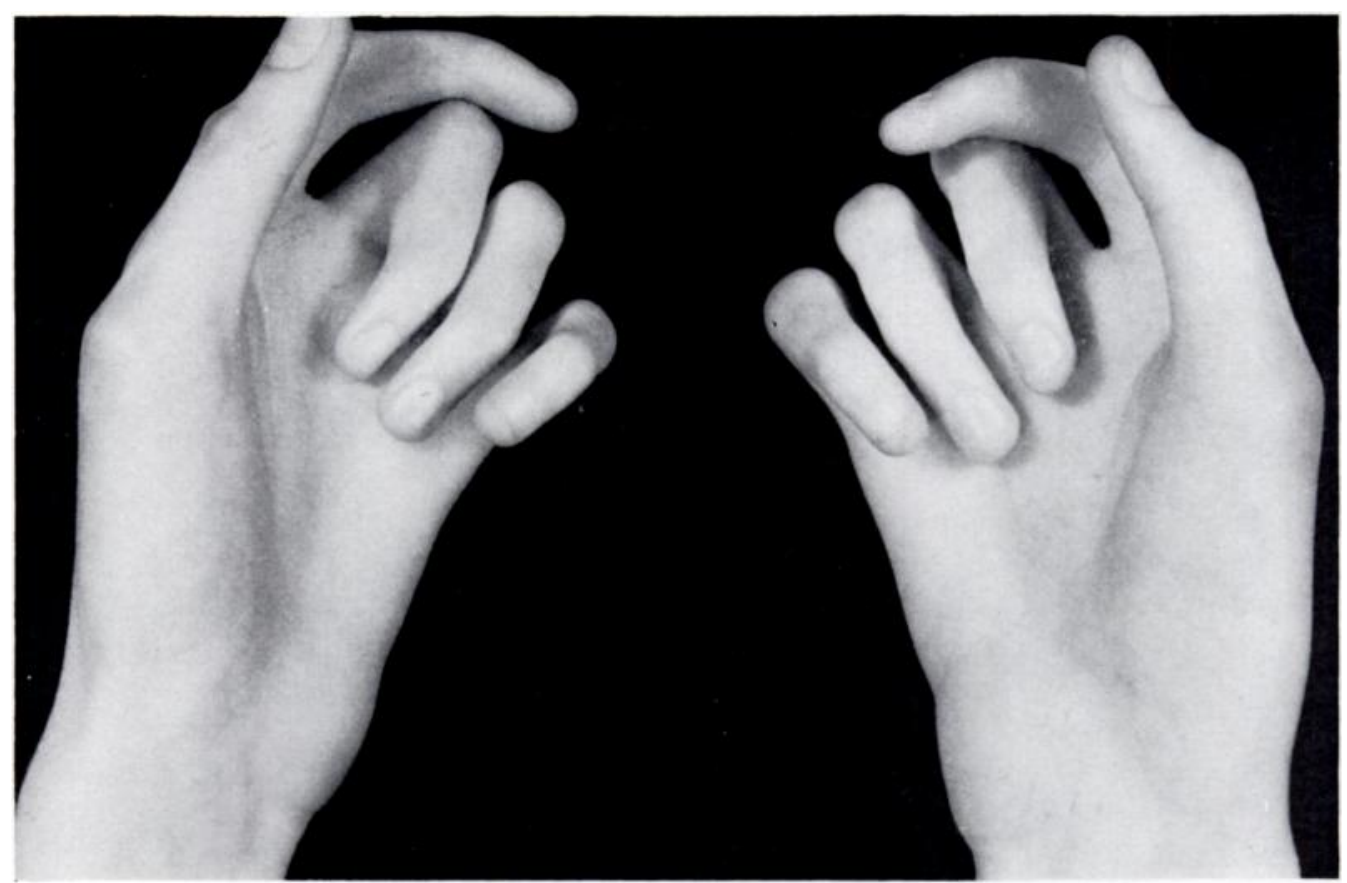

Fig. 28

The hands of a patient aged 22 years with Marfan's syndrome including dislocated lenses and scoliosis. Note the severe flexion contracture of the fingers.

\section{GENETIC FACTORS IN HOMOCYSTINURIA} AND IN MARFAN'S SYNDROME

The series are too small for formal analysis but each disorder shows an expected pattern of inheritance. Homocystinuria is thought to be of autosomal recessive inheritance and it was found that five of twenty-seven sibs (18.5 per cent) were affected, but all parents were normal, as expected in recessive inheritance. Marfan's syndrome is of autosomal dominant inheritance: seven of the sixteen parents of the eight index patients were affected and nine of thirteen sibs (just over the expected figure of 50 per cent first degree relatives affected). It was also established that eight of forty second-degree relatives had the disorder ( 20 per cent, near the expected figure of 25 per cent).

\section{DISCUSSION}

Published reports on skeletal abnormalities in homocystinuria do not indicate the relative frequency of severe or mild changes. In this series approximately three-fifths of the patients had moderate or severe skeletal abnormalities and two-fifths had only mild changes, though possibly in some of them the changes may become more severe as they grow older. Patients with normal intelligence and late lens dislocation are more likely to have milder changes. Brenton, Cusworth, Dent and Jones (1966) showed photographs at ages two and a half, six and fourteen years of the patient illustrated here in Figure 3 at eighteen years. This whole series illustrates dramatically the abnormalities of bone growth.

With regard to the comparison of skeletal abnormalities in homocystinuria and Marfan's syndrome, Smith (1967) has said that the only difference in the skeleton in homocystinuria from that in Marfan's syndrome is that there is marked generalised osteoporosis. Defining the range of skeletal abnormalities in Marfan's syndrome is difficult because these abnormalities are themselves used as a basis for diagnosis, and the milder cases may escape detection. Height and skeletal proportions do not differentiate the two. Results reported here suggest that 
arachnodactyly and severe scoliosis are more common in Marfan's syndrome, but the incidence of severe scoliosis in this series reflects in part the selection of some patients from a scoliosis clinic. Both arachnodactyly and severe scoliosis can occur in homocystinuria and their presence therefore does not assist diagnosis in the individual patient.

Widening of the epiphyses and metaphyses was not considered important by Morreels and colleagues (1968), but large knees were a striking feature of the patients with severe homocystinuria described here. Also, femoral heads and necks were frequently abnormal in shape. Other authors have commented on the biconcave vertebrae and osteoporosis of the spine in homocystinuria and we confirm this, but have also noted flat and elongated vertebrae without biconcavity, unlike those found in osteoporosis from other causes.

These epiphysial, metaphysial and vertebral changes of homocystinuria do not appear in Marfan's syndrome. By contrast, in some patients the vertebrae were of unusual vertical depth. (A similar appearance is commented upon by Nelson (1958) in his description of four patients with Marfan's syndrome.) Although these points may be suggestive of one disease rather than the other, consideration of skeletal features alone is not sufficient for diagnosis. An indisputably dominant pedigree, or aortic dissection in the patient or his near relatives, favours Marfan's syndrome. Mental retardation and thrombotic episodes suggest homocystinuria. The diagnosis is confirmed by a positive urine test for homocystine.

It is important that the correct diagnosis be made for two reasons. First, there is the risk of thrombosis in homocystinuria which may be greater after surgical operations. Secondly, in more than half the patients with homocystinuria the biochemical state can be made normal with pyridoxine therapy or a low protein diet (Barber and Spaeth 1967, Brenton and Cusworth 1971). It has not been proved that treatment causing disappearance of homocystine from blood and urine benefits the patient clinically, but it is possible that it will protect him from the thrombotic risk.

The cause of this thrombotic tendency in untreated homocystinuria is not known. There is some evidence that it may be due to abnormal platelet stickiness (McDonald, Bray, Field, Love and Davies 1964) and that homocystine is responsible for this (Barber and Spaeth 1969). The risk of thrombotic episodes cannot be assessed accurately, but approximately a quarter of the homocystinuric patients described here have had thromboses (Table III), and others may have had occult episodes. Thromboses occur in veins and arteries and may be cerebral, coronary, renal, mesenteric or in peripheral veins with pulmonary emboli. The high incidence of thrombotic deaths in published series (mostly occurring under the age of thirty years) may not reflect the actual risk in homocystinuria, because a patient with a life-threatening thrombosis is more likely to be seen in hospital than is one with mild homocystinuria and few symptoms. It is likely therefore that observations so far published overestimate the thrombotic risk. Nevertheless, it is a real and important feature of the disease.

There is clinical evidence that in both Marfan's syndrome and homocystinuria there is a connective tissue defect. The evidence is more conclusive in Marfan's syndrome because of proven changes in the aortic media leading to dissection. Dissecting aneurysm has not been noted in homocystinuria but metachromatic medial degeneration of the aorta has been described by Gibson and colleagues (1964), and it is possible therefore that a defect of the aortic media is a feature of this disease also. It is commonly assumed that the defect is in the structure of collagen or elastin, or both. Recent work on cross linkages between peptide chains of collagen and elastin molecules has indicated the importance of lysine residues and their conversion to $\alpha$ amino-adipic acid $\delta$ semi-aldehyde. The aldehyde groups in adjacent peptide chains react to form cross linkages which are important in the mechanical properties of connective tissue, and when these are not developed the collagen is more soluble and mechanically inadequate.

A cross linkage abnormality could account for the defects in both disorders. Consideration of the similarities and differences of the two diseases leads one to suspect two very similar 
but not identical chemical defects but, in view of the different mode of inheritance, arising from two completely different mechanisms.

\section{SUMMARY}

1. Skeletal and other clinical features in twenty-three patients with homocystinuria have been compared with those in sixteen patients with Marfan's syndrome.

2. The two diseases are clinically similar but florid arachnodactyly and scoliosis are commoner in Marfan's syndrome, whereas widening of epiphyses and metaphyses of long bones is a distinctive feature of homocystinuria.

3. Patients with homocystinuria frequently have osteoporosis at a young age with a high incidence of vertebral involvement including biconcavity and flattening. Patients with Marfan's syndrome do not have osteoporosis and may have excessively tall vertebrae.

4. Mental retardation and thrombosis are common in homocystinuria and uncommon in Marfan's syndrome.

5. Homocystinuria is most probably inherited as an autosomal recessive and Marfan's syndrome as an autosomal dominant.

6. The two diseases should be differentiated because of the thrombotic risk in homocystinuria, and also because in this disease there is a possibility of treating the biochemical defect.

7. Although patients with homocystinuria may present to the orthopaedic surgeon with osteoporosis, severe genu valgum or scoliosis, the disease is an uncommon cause of these defects.

We would like to thank Professor C. E. Dent and Dr C. J. Hodson for their advice and encouragement. We thank, too, the many clinicians who referred patients with homocystinuria to University College Hospital, London.

\section{REFERENCES}

Achard, C., and Grenet, H. (1902): Persistance de la lymphocytose arachnoidienne, et des douleurs dans un cas de zona. Bulletins et Mémoires de la Société Médicale des Hôpitaux de Paris, 19, 1069.

Barber, G. W., and Spaeth, G. L. (1967): Pyridoxine Therapy in Homocystinuria. Lancet, 1, 337.

Barber, G. W., and Spaeth, G. L. (1969): The Successful Treatment of Homocystinuria with Pyridoxine. Journal of Pediatrics, 75, 463.

Brenton, D. P., and Cusworth, D. C. (1971): The Response of Patients with Cystathionine Synthase Deficiency to Pyridoxine. In Inherited Disorders of Sulphur Metabolism. Proceedings for the Eighth Symposium of the Society for the Study of Inborn Errors of Metabolism, 1970. Edited by N. A. J. Carson and D. N. Raine. Edinburgh and London: Churchill Livingstone.

Brenton, D. P., Cusworth, D. C., and Gaull, G. E. (1965): Homocystinuria. Metabolic Studies on 3 Patients. Journal of Pediatrics, 67, 58.

Brenton, D. P., Cusworth, D. C., Dent, C. E., and Jones, E. E. (1966): Homocystinuria. Clinical and Dietary Studies. Quarterly Journal of Medicine, 35, 325.

Carson, N. A. J., Dent, C. E., Field, C. M. B., and Gaull, G. E. (1965): Homocystinuria: Clinical and Pathological Review of Ten Cases. Journal of Pediatrics, 66, 565.

Cusworth, D. C., and Gattereau, A (1968): Inhibition of Renal Tubular Reabsorption of Homocystine by Lysine and Arginine. Lancet, ii, 916.

Fifld, C. M. B., Carson, N. A. J., Cusworth, D. C., Dent, C. E., and Neill, D. W. (1962): Homocystinuria, a New Disorder of Metabolism. Abstracts of the 10th International Congress of Pediatrics, Lisbon, p. 274.

Gerritsen, T., and Waisman, H. A. (1964): Homocystinuria, an Error in the Metabolism of Methionine. Pediatrics, 33, 413.

Gibson, J. B., Carson, N. A. J., and Neill, D. W. (1964): Pathologic Findings in Homocystinuria. Journal of Clinical Pathology, 17, 427.

Greulich, W. W., and Pyle, S. I. (1959): Radiographic Atlas of Skeletal Development of the Hand and Wrist. Second edition. Stanford, California: Stanford University Press.

MacCarthy, J. M. T., and Carey, M. C. (1968): Bone Changes in Homocystinuria. Clinical Radiology', $19,128$.

VOL. 54 B, NO. 2, MAY 1972 
McDonald, L., Bray, C., Field, C., Love, F., and Davies, B. (1964): Homocystinuria, Thrombosis and the Blood-Platelets. Lancet, i, 745.

McKusıck, V. A. (1966): Heritable Disorders of Connective Tissue. Third edition, chapter 3, p. 38. Saint Louis: The C. V. Mosby Company.

McKusıck, V. A. (1968): Mendelian Inheritance in Man. Second edition, pp. 62, 265. Baltimore: The Johns Hopkins Press.

MARfan, A. B. (1896): Un cas de déformation congénitale des quatre membres, plus prononcée aux extrémités, caractérisée par l'allongement des os avec un certain degré d'amincissement. Bulletins et Mémoires de la Société Médicale des Hôpitaux de Paris, 3rd Series, 13, 220.

Morreels, C. L., Fletcher, B. D., Weilbaecher, R. G., and Dorst, J. P. (1968): The Roentgenographic Features of Homocystinuria. Radiology, 90, 1150.

Murray, R. O., and Duncan, C. (1971): Athletic Activity in Adolescence as an Etiological Factor in Degenerative Hip Disease. Journal of Borie and Joint Surgery, 53-B, 406.

Nelson, J. D. (1958): The Marfan Syndrome, with Special Reference to Congenital Enlargement of the Spinal Canal. British Journal of Radiology, 31, 561.

Schimke, R. N., McKusick, V. A., Huang, T., and Pollack, A. D. (1965): Homocystinuria. Study of 20 Families with 38 Affected Members. Journal of the American Medical Association, 193, 711.

Sinclair, R. J. G., Kitchin, A. H., and Turner, R. W. D. (1960): The Marfan Syndrome. Quarterly Journal of Medicine, 53, 19.

Sмiтн, S. W. (1967): Roentgen Findings in Homocystinuria. American Journal of Roentgenology, $100,147$. WEVE, H. (1931): Über Arachnodaktylie. (Dystrophia mesodermalis congenita, Typus Marfan). Archiv fiir Augenheilkunde, 104, 1. 